\title{
Impact of Large Scale Permeability Heterogeneity in the Optimisation of a WAG Process in Tertiary Conditions
}

\author{
Duquerroix J. P., Kalaydjian F. \\ IFP, France
}

\begin{abstract}
Copyright 1995, Steering Committee of the European IOR - Symposium.
This paper was presented at the Oth. European IOR - Symposium in Vienna, Austria, May 16 - 17, 1995

This paper was selected for presentation by the Steering Committee, following review of information contained in an abstract

submitted by the author(s). The paper, as presented has not been reviewed by the Steering Committee.
\end{abstract}

\section{Abstract}

Among the Improved Oil Recovery (IOR) processes, Water Alternating Gas (WAG) injection process seems to have a wide potential in the North Sea. The rule of thumb is still in use and both industry and research need to design procedures to ensure broader application of WAG technology.

This process is characterized by a sequential injection of water and gas slugs whose sizes, which are dependent on the reservoir characteristics, have to be optimized. The aim of this paper is to study the impact of reservoir heterogeneties on the efficiency of this IOR process, through a comprehensive approach combining reservoir characterization and modelling. In order to do so, 2D numerical simulations were performed, using a black-oil three-phase reservoir simulator, on both twolayer reservoirs and equiprobable stochastically defined 2D images of a reservoir. The reservoir consists of two lithofacies distributed among ten horizontal layers.

In this paper, we study systematically the influence of lithofacies proportion, correlation length, permeability anisotropy ratio and slug sizes.

We derive that, for two-layer reservoirs, within the range of slug sizes considered and with a slug ratio equal to unity, the greater the duration of the slug injection, the greater the oil recovery, with a marked influence of the heterogeneity location on this recovery. The anisotropy can be fruitful or not depending on the cases.
Concerning simulations performed in stochastic reservoirs, results are given in terms of recovery distribution analysis. The number of required realizations, for a given situation, depends on the correlation length. For quite all simulations, the increase of correlation length lowers the level of oil recovery. For the slug sizes considered, in the isotropic case, the oil recovery increases with the slug size, while when permeability anisotropy occurs, the reverse trend is observed.

\section{Introduction}

Gas injection not stabilized by gravity may result, due to unfavourable mobility ratio, in relatively low recovery. This drawback can be avoided by injecting water and gas alternatively or simultaneously 1 . The main interest of the WAG process is twofold:

-the presence of water reduces the gas mobility, -the sweeping of the reservoir is improved as the gas can push oil out of zones where oil was captured during waterflooding.

Petroleum engineers need both economical and technical criteria to be in a position to take decisions when applying this process to actual reservoirs. So far, empirical rules are still in use. Without accurate information, gas and water are injected with a volume ratio of one and the pore slug determined by experience.

Our aim in this paper is to give some insights into the process optimization taking heterogeneity into account.

Reservoirs with fixed heterogeneity as well as stochastic images will be considered. 
While studying the optimization of WAG process, 2D simulations are performed to be able to take gravity effects into account as gas and water are injected successively.

Numerous parameters may influence tertiary oil recovery. They can be grouped into two classes. Firstly let us consider those connected with the reservoir description:

- the horizontal and vertical correlation length of facies,

- the global proportions of facies (in this paper two facies are considered),

- the facies permeability,

- the inter-well distance,

- the anisotropy ratio of permeability. The vertical permeability is commonly one-tenth oi the horizontal one,

- the reservoir wettability.

Secondly, let us see the parameters in relation with the production conditions. Those conditions may depend for example on the availability of gas during the year but also on the intrinsic value of gas. One can list:

- water and gas flow-rates,

- the total amount of gas to be injected,

- the fluid itself (mobility ratio),

- the water and gas slug sizes,

- the completions distribution (in this work the whole producing zone is completed),

- the injecting zone corresponding to gas or water.

The knowledge of three-phase flow is still under development and such phenomena as oil spreading should also be considered.

This paper summarizes results of these 2D numerical simulations. The reservoir simulator ATHOS R, a 3D,3 phase fully compositional reservoir simulator, in its black-oil version, is used. The andysis highlights the relative influence of viscous/gravity ratio 2 as well as the extension of the three phase zone ${ }^{3}$. The three -phase model is briefly described 4 .

The geostatistical simulators provide equiprobable images of a reservoir from the knowledge of information at wells and it is thus necessary, for a given situation, to carry out a representative number of corresponding fluid-flow simulations, large enough to obtain acceptable distribution results.

A thorough description of hundreds of simulations is given in terms of tertiary oil recovery distribution.

\section{Description of Simulations}

\section{Geostatistical simulator}

The commercial simulator Heresim 3D $R$ was used for all the geostatistical simulations. The input parameters are listed in table 1.

\begin{tabular}{|l|l|}
\hline cell size & $\begin{array}{l}\mathrm{DX}=\mathrm{DY}=10 \mathrm{~m} \\
\mathrm{DZ}=5 \mathrm{~m}\end{array}$ \\
\hline cells number & $\begin{array}{l}\mathrm{nX}=69, \mathrm{nY}=5, \\
\mathrm{nZ}=10\end{array}$ \\
\hline $\begin{array}{l}\text { vertical correlation } \\
\text { length }\end{array}$ & $10 \mathrm{~m}$ \\
\hline $\begin{array}{l}\text { horizontal correlation } \\
\text { length }\end{array}$ & $50,100,250,500 \mathrm{~m}$ \\
\hline $\begin{array}{l}\text { facies permeability } \\
\text { (x10-12 m } 2)\end{array}$ & $\begin{array}{l}\mathrm{k} 1=1, \mathrm{k} 2=0.01 \\
\text { constant per facies }\end{array}$ \\
\hline $\begin{array}{l}\text { conditioning well } \\
70 \% \mathrm{f} 1 \text { (case } 1) \\
50 \% \mathrm{f} 1 \text { (case 2) }\end{array}$ \\
\hline global proportion & $\begin{array}{l}70 \% \mathrm{f} 1 \text { (case 1) } \\
50 \% \mathrm{fl} \text { (case 2) }\end{array}$ \\
\hline
\end{tabular}

table 1

\section{Fluid-flow simulator}

The commercial simulator ATHOS $\mathrm{R}$ was used for all the fluid-flow simulations. Homogeneous and two-layer reservoirs were firstly considered. In this latter case $70 \%$ f 1 or $50 \% \mathrm{f} 1$ conditions are considered, the more permeable zone corresponding to the upper or lower layers. The crosssection containing the conditioning well was chosen for 2D simulations corresponding to stochastic conditions. The input parameters are listed in table 2.

\begin{tabular}{|l|l|}
\hline cell size & $\begin{array}{l}\mathrm{DX}=\mathrm{DY}=10 \mathrm{~m} \\
\mathrm{DZ}=5 \mathrm{~m}\end{array}$ \\
\hline cells number & $\begin{array}{l}\mathrm{nX}=49, \mathrm{nY}=1 \\
\mathrm{nZ}=10\end{array}$ \\
\hline $\mathrm{Kv} / \mathrm{Kh}$ & 0.1 or $\mathrm{l}$ \\
\hline $\mathrm{F}$ & .2 for $\mathrm{fl}$ and $\mathrm{f} 2$ \\
\hline $\begin{array}{l}\text { viscosities } \\
\text { (mPa.s) }\end{array}$ & $\begin{array}{l}\mathrm{mw}=0.6, \mathrm{mo}=0.63 \\
\mathrm{mg}=0.0161\end{array}$ \\
\hline $\begin{array}{l}\text { Pressure } \\
(\mathrm{x} 1.013105 \mathrm{~Pa})\end{array}$ & $\begin{array}{l}\mathrm{Pb}=100 \\
\mathrm{P}=120\end{array}$ \\
\hline Residual satur:stion & $\begin{array}{l}\text { Sorw }=0.4 \\
\text { Sorg }=0.1\end{array}$ \\
\hline
\end{tabular}

table 2 
There is no up-scaling between geostatistical and fluid-flow simulations. Stone-Dietrich's model was used to calculate kro for three-phase flow ${ }^{4}$. Our intention in this paper is not to compare extensively the different three-phase flow models. These different approaches may lead to large discrepancies 3 .

The relative permeabilities used were experimentally determined and presented formerly 5. Water-oil and gas-oil relative permeability systems exhibit hysteresis for the non-wetting phase. This hysteresis is calculated by Land and Killough's model 6,7 . This has been found to be determining in a previous study 8 .

No capillary effects were considered in the WAG simulations. Simulations were only performed under tertiary conditions. The resulting oil recovery was calculated as a function of the two two-phase residual oil saturations Sorw and Sorg.

\section{Results and Discussion}

\section{Homogeneous case}

At first let us show up the interest of WAG injection compared o gas injection. For this purpose, an homogeneous reservoir with a permeability of $10^{-12} \mathrm{~m}^{2}$ was considered. Isotropic and anisotropic conditions were successively examined. The slug size was varied between $5 \%$ and $20 \%$ PV for the isotropic case, the same amount of gas and water being injected for each case. The gas water slug ratio is equal to unity. After a global injection of 1.2PV, we obtain for tertiary oil recovery the results presented in figure 1. Oil recovery is always alculated as a function of the amount of oil that can be recovered (Sorw-Sorg). Sorw and Sorg are respectively the residual oil saturation after waterflooding and gasflooding.

For WAG injection, we observe that the greater the slug size, the greater the oil recovery as the sweep efficiency increases with the slug size. For a given slug size, the anisotropic case yields lower recovery. The vertical sweep efficiency is less efficient in this situation. With gas injection, the tertiary oil recovery is reduced by more than $25 \%$.

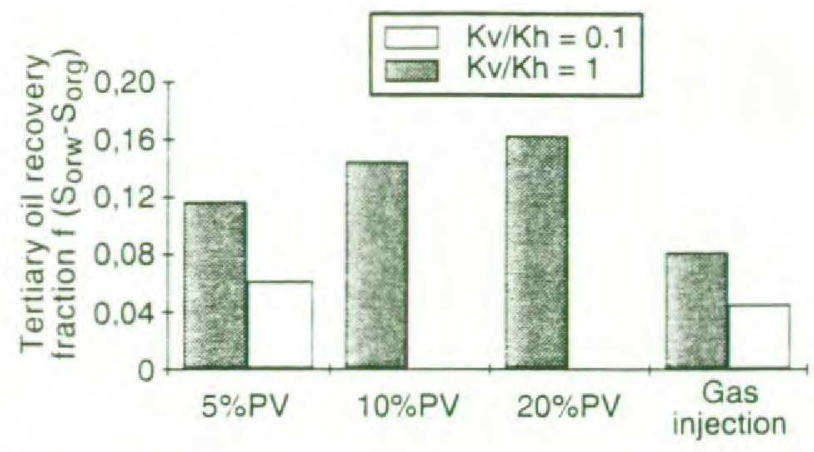

figure 1. Comparison of WAG and continuous gas injection and effect of anisotropy in the case of an homogeneous reservoir.

\section{Two-layer system}

Then four different two-layer reservoirs were considered with either $70 \% \mathrm{fl}$ or $50 \% \mathrm{fl}$ and for the anisotropic case.

The more permeable zone (facies $\mathrm{f} 1$ ) occupies the seven top layers or seven bottom layers ( $70 \% \mathrm{fl}$ ) on the one hand or the five top layers or five bottom layers $(50 \% \mathrm{f} 1)$ on the other hand. We compare gas injection and WAG injection for a slug size of $5 \% \mathrm{PV}$. The results are displayed in figure 2.

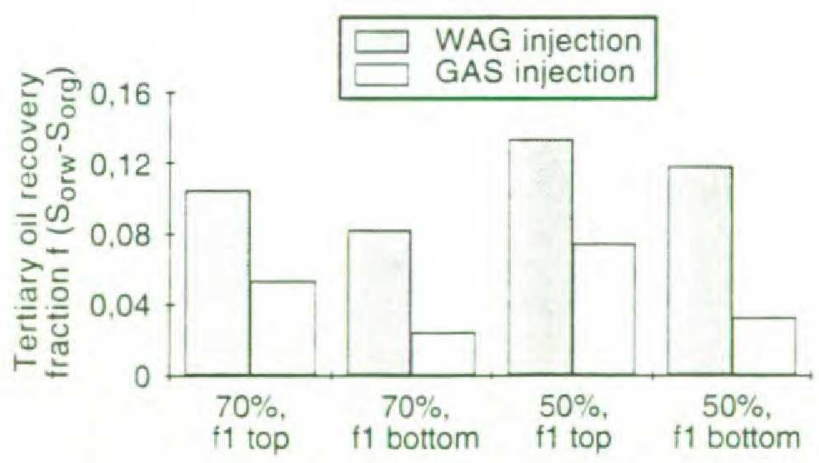

figure 2. Comparison of WAG and continuous gas injection for two-layer systems in terms of tertiary oil recovery.

With gas injection, the decrease in oil recovery is even much larger for the layered reservoirs than in the homogeneous case. We can see that the recovery reduction is $50 \%$ (resp. $70 \%$ ) when $\mathrm{fl}$ lies at the top (resp. bottom) of the layers.

Moreover one can notice that for $5 \% \mathrm{PV}$ and in the anisotropic case the oil recovery is higher for 50 than for $70 \% \mathrm{fl}$. There is probably an optimum at $50 \% \mathrm{f} 1$ due to the particular sweeping of the reservoir in relation to anisotropy. 


\section{Slug size effect and anisotropy}

Then the influence of slug size during WAG injections for two-layer reservoirs was analysed (figures 3 and 4).

For this purpose, twelve more simulations were carried out, with $70 \%$ f 1 or $50 \%$ f1 (facies f1 at top or bottom of the reservoir) in the isotropic case and three slug sizes $(5 \%, 10 \%$ and $20 \%$ PV).

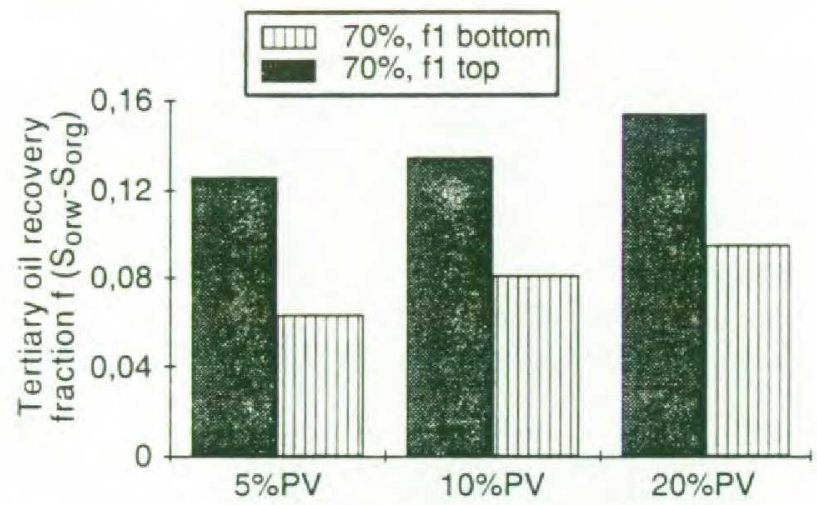

figure 3. WAG injection in two-layer systems with $70 \%$ of the more permeable facies.

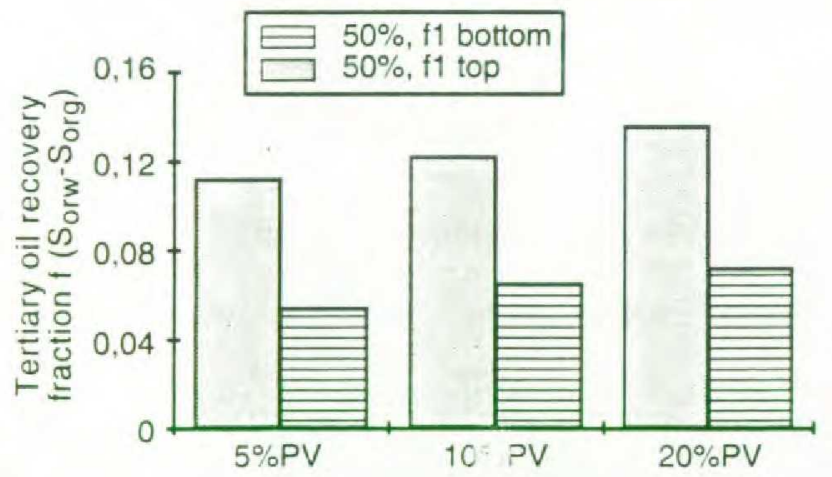

figure 4. WAG injection in two-layer systems with $50 \%$ of the more permeable facies.

The same trend can be noticed at $50 \%$ and $70 \% \mathrm{fl}$ :

-the greater the slug size, the greater the tertiary oil recovery with increase of 20 to $50 \%$. -when the more perm ble zone is located at the top of the reservoir, the oil recovery is twice as much as what was obtained in the other case.

A better oil recovery is obtained in the anisotropic rather than in the isotropic case if the more permeable zone is located at the bottom of the reservoir. This conclusion is valid for both 50 or $70 \% \mathrm{fl}$ cases. There is a competition between gravitary effects and anisotropy (figures 5 ).

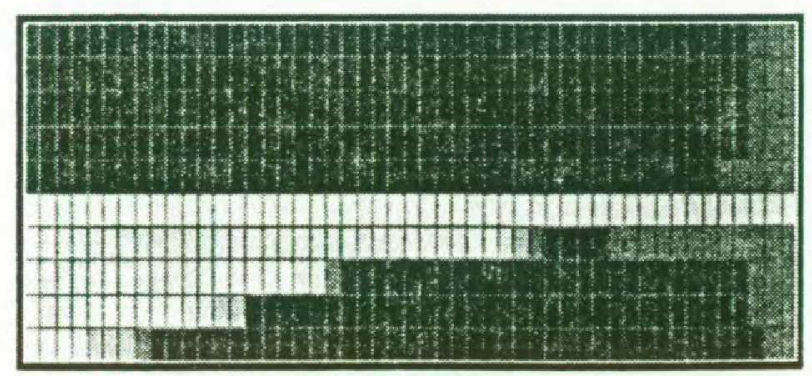

$K v / K h=0,1$

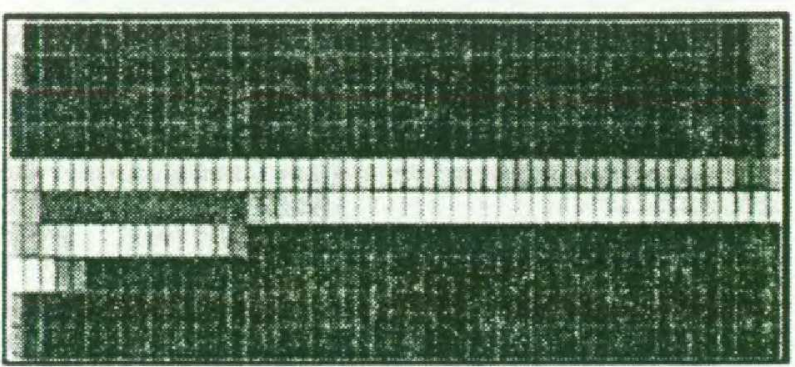

$K v / K h=1$

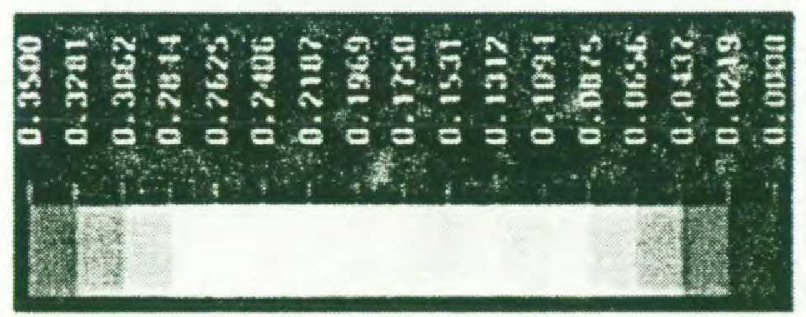

Gas Saturation at 0,08 PV

figure 5 Influence of anisotropy on sweeping.

\section{Influence of heterogeneity location}

When the more permeable zone is located at the top of the reservoir and whatever the slug size for both 50 and $70 \% \mathrm{fl}$ cases the oil recovery is higher. Stone 2 found the reverse trend with an anisotropy ratio of 0.25 and permeability ratios of 3,6 and 9 for a simultaneous injection of gas and water.

For sake of interpretation we have considered the bulk fraction of the reservoir where three-phase flow occurs. that is to say, when the product of the three three-phase relative permeabilities is not zero. The lowest value of relative permeability considered was $10^{-5}$

The same result stands with a realistic value of $10^{-3}$.

\section{Three-phase flow extension}

The figure 6 illustrates the coincidence of the increase of the three-phase zone and of the gas injection. The cycle duration in this situation is $20 \% \mathrm{PV}$. 


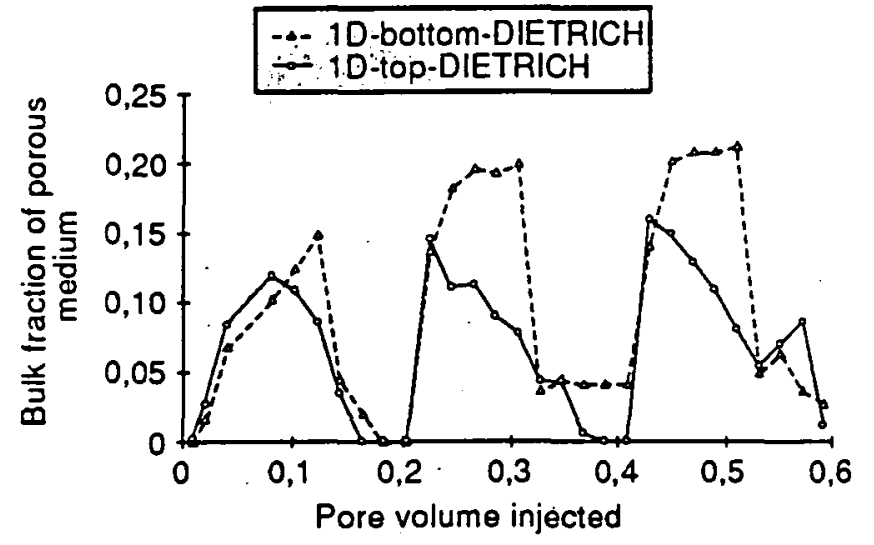

figure 6. Three-phase region with Stone-Dietrich's model (slug size 10\%PV).

There is up to $20 \%$ of the reservoir where threephase flow occurs. The higher oil recovery figure does not correspond to the higher extent of the three-phase region. This is in relation to the threephase oil relative permeability isoperm shape (figure 7).

There is no oil saturation lower than the residual oil saturation to gas in this situation. An other three-phase model was tested where the threephase oil relative permeability is calculated as an interpolation between the two two-phase limits.

It is referred to as a graphical method 9 in the following.

The corresponding isoperms $(0.00,0.05,0.10$, $0.15,0.20,0.25,0.30$ ) are represented in figure 8 .

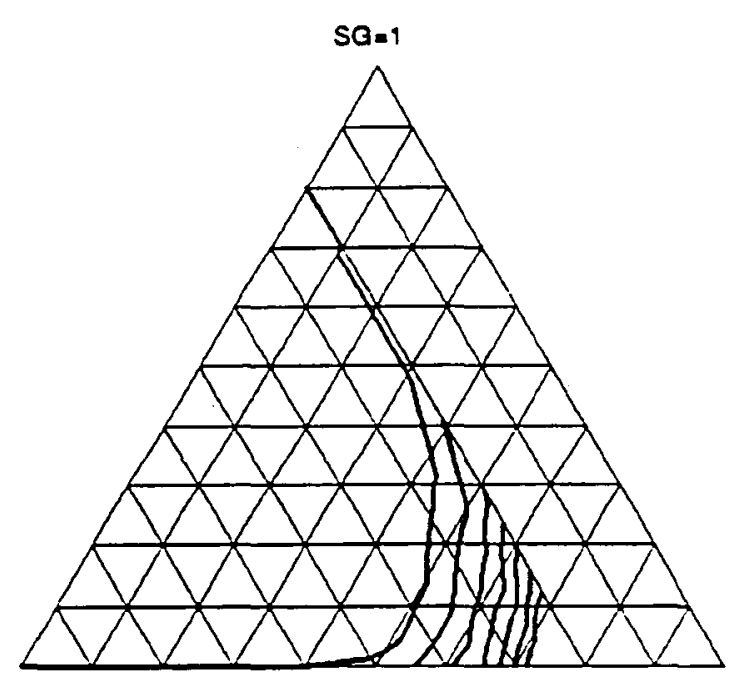

SW-1

SO-1

CRAINAQE GAS-OIL

STONE-DIETRICH MODEL

figure 7. Three-phase oil relative permeability isoperms with Stone-Dietrich'model.

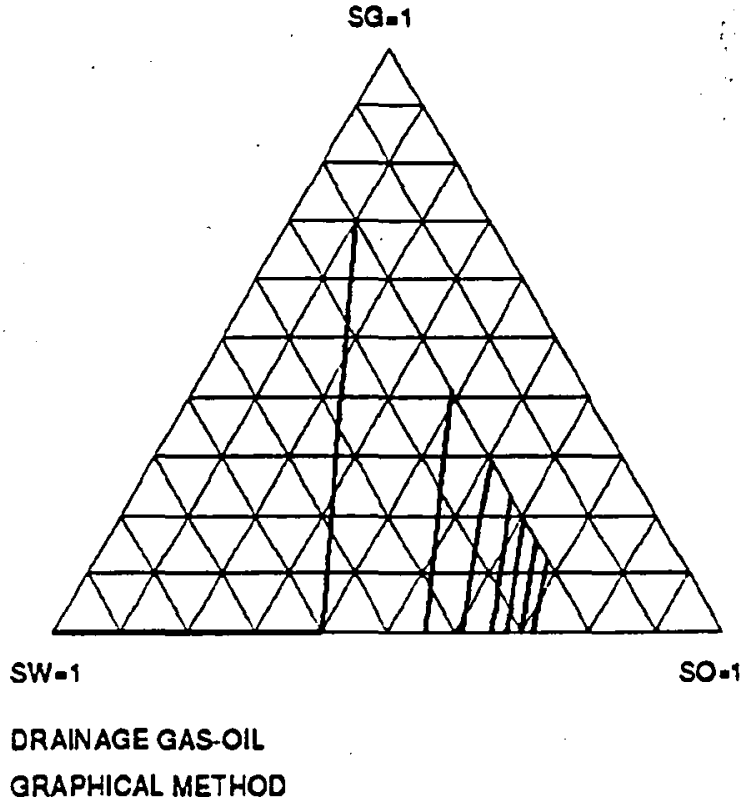

figure 8. Three-phase oil relative permeability isoperms with the graphical model.

\section{Influence of the three-phase model}

We have then performed the same simulations as previously in figure 6 , but with this second three-phase model. The oil recovery should be higher as more oil can be displaced.

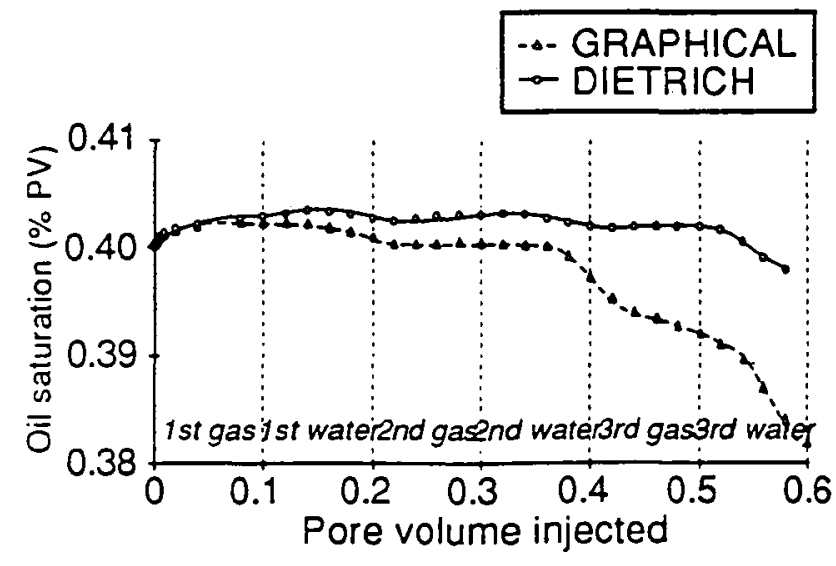

figure 9. Global oil saturation versus time. Comparison of Stone-Dietrich's and graphical model.

Figure 9 brings out the oil saturation gap at 0.6 PV when the three-phase model used is whether Stone-Dietrich's one or the graphical method when $\mathrm{fl}$ lies at the bottom of the reservoir. In the next figure (figure 10) the three-phase bulk fraction is represented for the graphical method. 


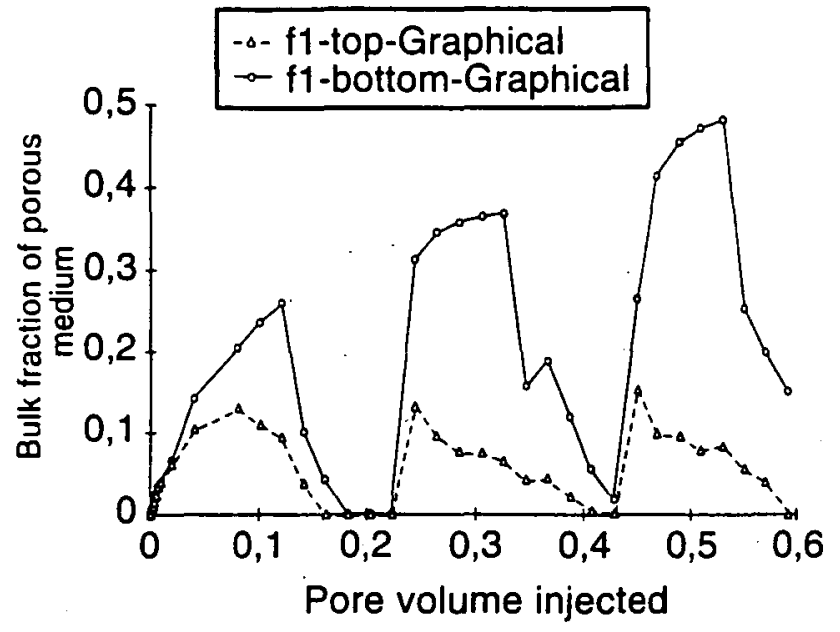

figure 10. Three-phase region with the graphical method (slug size 10\%PV).

In this case, the three-phase zone goes up to $50 \%$ of the bulk fraction of the reservoir. So, with our data, there is no relationship between the importance of the three-phase zone and the level of oil recovery.

\section{Coarser grid analysis}

To go on with our investigations, for sake of simplification of representation, an analysis with a coarser grid was performed. In order to do so, seven cells in the $X$ direction and two in the $Z$ direction were grouped. Thus we have seven coarser cells in the horizontal direction and five in the vertical one. The idea was to consider the evolution of mean saturation. In figure 11 , water saturation distribution at $0.4 \mathrm{PV}$, when the more permeable zone is located at the top or at the bottom of the reservoir, is represented.

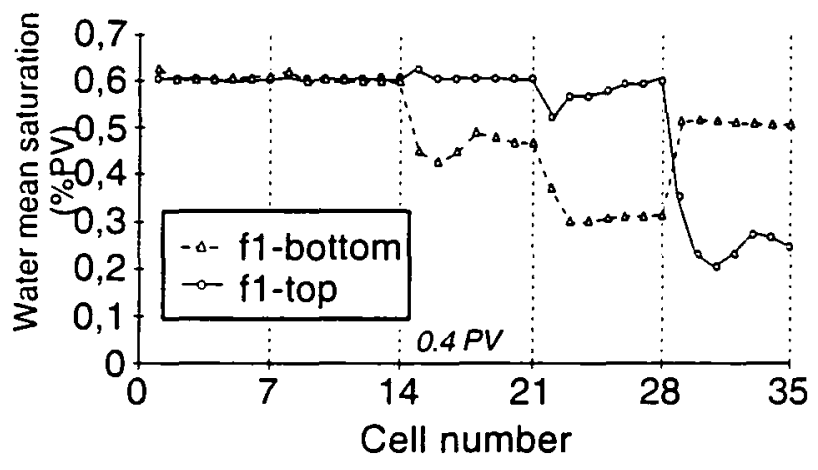

figure 11. Global mean saturation versus coarser grid number $(N X=7, N Z=2)$.

This time of $0.4 \mathrm{PV}$ was chosen because it corresponds appoximatively to the oil breakthrough (figure 9) and marked different behaviours can be noticed in the two situations. The water saturation varies between 1-Sorw and Swi. When fl lies at the bottom (resp. top) of the reservoir, the desaturation occurs in the layers 3 and 4 (resp. 5). In fact, due to gravity effects, there is relatively more water in layers 3 and 4. Gas pushes water out of these zones.

Finally, overall water and oil mean saturations are presented in figures 12 and 13 with the graphical method used to generate the threephase model. The same results as with StoneDietrich's model are obtained.

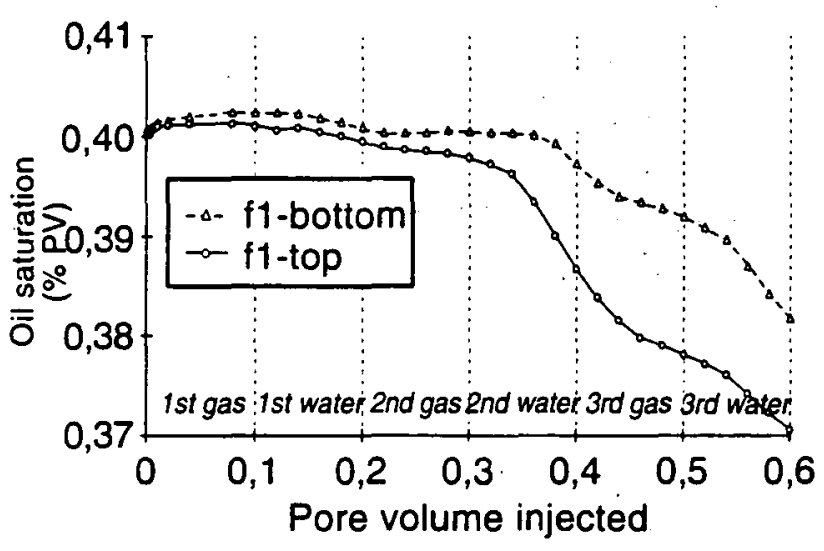

figure 12. Global oil saturation versus time for different two-layer systems.

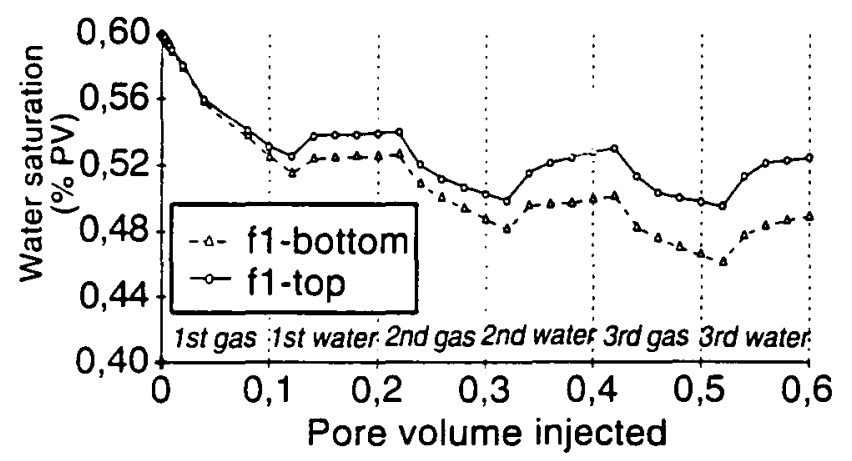
figure 13. Global water saturation versus time for
different two-layer systems.

At $0.6 \mathrm{PV}$ there is a significative relative difference of $3 \%$ (resp. 23\%) for oil (resp. water) saturation. When the more permeable zone is located at the bottom, water is displaced preferentially to oil due to gravity effects but also because of the quite high value of the end-point of the water relative permeability in our system. This result was also confirmed for an absolute permeability ratio of 10 . 


\section{Stochastically defined reservoirs}

Then we have analysed results of stochastically defined reservoirs. The procedure described hereafter was followed.

Several equiprobable images of the reservoir are generated ( 4 in the example) by a geological model, then reservoir simulations are performed.

\section{METHODOLOGY}

Geological image

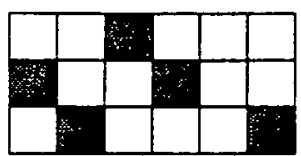

1

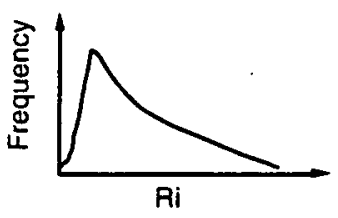

4
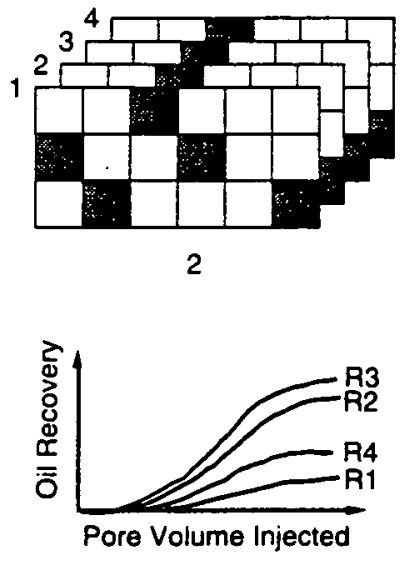

3 figure 14. Methodology followed (steps 1 to 4) from equiprobable images of the reservoir to tertiary oil recovery distribution.

\section{Number of realisations}

The levels of tertiary oil recovery are analysed (in this example, the recovery corresponding to the 3 rd image is the highest) and the distributions of these recoveries are plotted.

Besides the anisotropy ratio, the major parameter for heterogeneous reservoirs is the correlation length of facies. The correlation length of a given facies is the maximum distance for which two separate points will correspond to the same facies. We firstly performed the same number of simulations, 30 realisations or seeds, whatever the considered case. The analysis of tertiary oil recovery distributions showed that this number should be fixed according to the correlation length. Figure 15 brings out the influence of the number of realisations on the shape of distributions for a correlation length of $50 \mathrm{~m}$, in an anisotropic case. The facies permeability ratio is 100 and the global proportion of $\mathrm{fl} 70 \%$. In this case, the slug sizes of gas and water are equal to $10 \%$ PV.

The number of seeds alters significatively the shape of the tertiary oil distribution. What we found out was that a larger number of seeds with a decreasing correlation length was necessary to define a more regular distribution. When the correlation length is equal to the inter-well distance, an infinite number of realizations would be required as, in this case, the images are independent and the standard deviation of the distribution is larger.

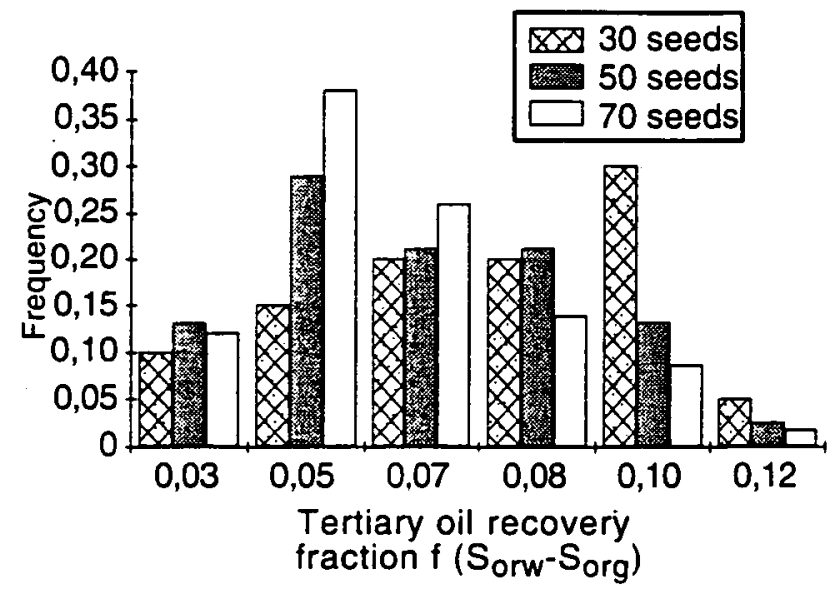

figure 15. Distribution of tertiary oil recovery versus the number of seeds $(k 1 / k 2=100, \% f 1=70, X$-corr. length $=50 \mathrm{~m}$, slug size $=10 \% \mathrm{PV}$ ).

With 70 realisations, the tertiary oil recovery is concentrated around 0.05 while with 30 seeds the : value represents one-third of the distribution.

\section{Influence of correlation length and anisotropy}

We have then considered the influence of slug size (between 5 and 20\%PV) and anisotropy in relation to correlation length. In fact the correlation length is normalised by the inter-well distance.

In the isotropic case we obtain the results presented in the figure 16.

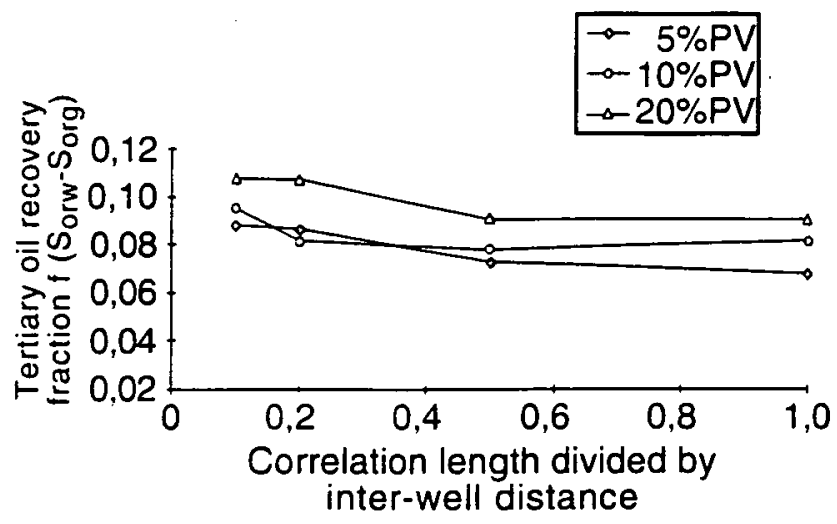

figure 16. Effect of slug size and corr. length in the isotropic case. 
For these stochastically heterogeneous simulations, the three-phase model used is StoneDietrich's one. The tertiary oil recovery was determined at 1.2 PV.

Each point on this figure represents the arithmetic mean of up 50 to 70 reservoir simulations, corresponding each to equiprobable images, depending on the correlation length. The larger the slug size, the higher the tertiary oil recovery, although the global extent of variation lies between 0.07 and 0.12 . The general trend is a small reduction of this recovery level with an increase of the correlation length. We have seen previously, with two-facies simulations, the large influence of anisotropy and figure 17 now highlights its impact on the parameters investigated in the isotropic situation.

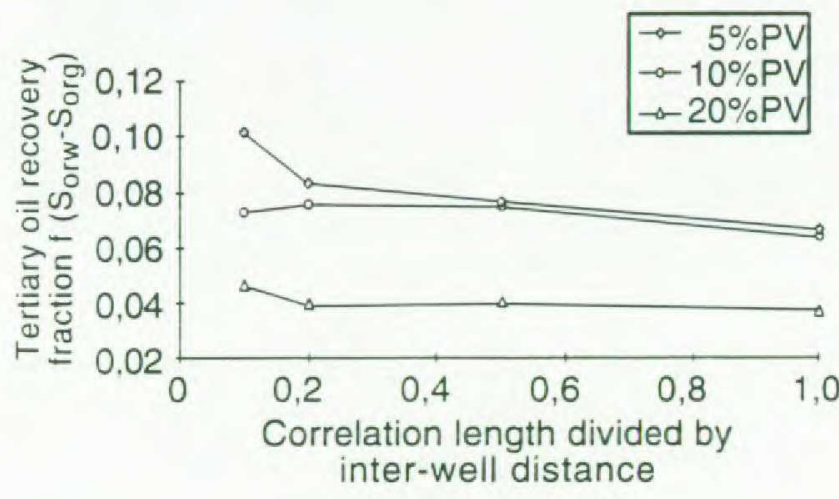

figure 17. Anisotropic case.

In the anisotropic case, the greater the slug size, the lower the tertiary oil recovery, with a larger range variation for oil recovery, between 0.02 and 0.12 . than in the isotropic case.

\section{Heterogeneity location}

These results are connected to the heterogeneity distribution within the reservoir but also to gravitary effects. We have considered a particular geological image. According to the correlation length chosen. e found for the eighth layer a more or less important extension of the facies 2 zone. This layer was previously the upper limit of our fl-bottom system. We have thus simulated additional two-layer systems to understand the impact of a given length of facies $\mathrm{f} 2$ on the eighth layer (figure 18).

We performed six simulations in both anisotropic and isotropic conditions with slug size between 5 and $20 \%$ PV. The global fl percentage is $96 \%$.

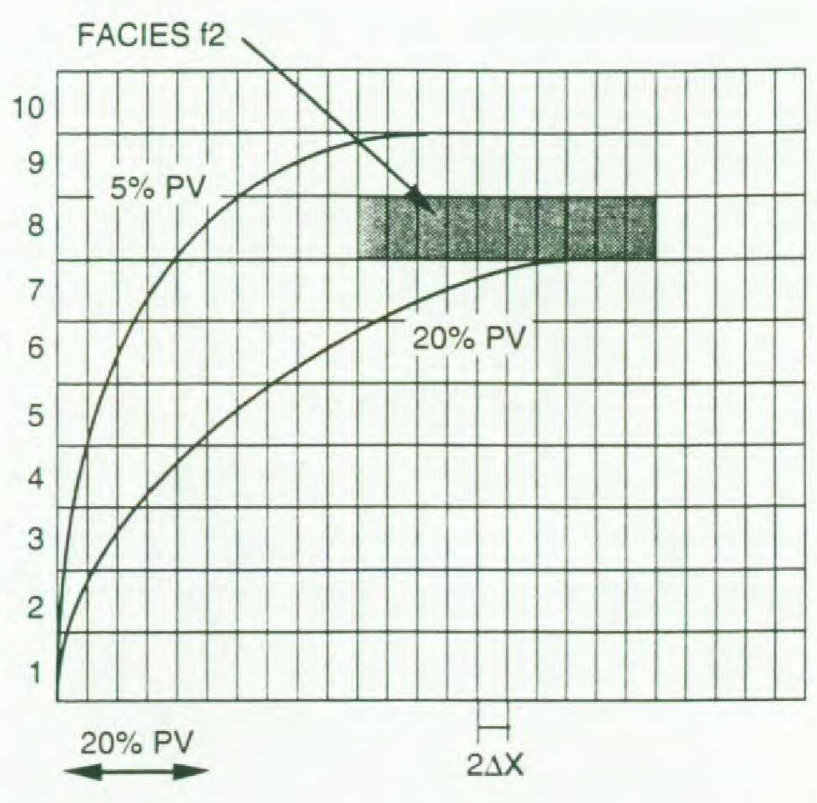

\section{figure 18. Effect of a less permeable zone hindering the propagation of the gas tongue function of the slug size.}

What we observed in the isotropic conditions, for instance at $10 \% \mathrm{PV}$ is a drastic reduction of tertiary oil recovery of $30 \%$ (resp. $47 \%$ ) compared to the previous f1-bottom (resp. f1-top results. This recovery is calculated at $0.6 \mathrm{PV}$. The central facies $\mathrm{f} 2$ hinders the propagation of the gas tongue. We obtain a reduction of the recovery with the increase of the slug size. Depending on the slug size, the gas will sweep more or less efficiently the upper layers. If the slug size is not too large compared to the available distance between the injecting well and the less permeable zone, the gas will reach the upper layers otherwise its progression upwards will be stopped. Then the conclusion of the previous fltop and fl-bottom applies.

In the anisotropic conditions, at $5 \% \mathrm{PV}$ the tertiary oil recovery is $70^{\circ}$ higher than when no permeability anisotropy curs. Again there is a competition between sravitary effects and anisotropy. With an increase of slug size from $5 \%$ to $20 \%$ PV a tertiary oil recovery reduction of $20 \%$ can be noticed as in the stochastically defined case.

\section{Influence of facies global percentage}

An other set of simulations was performed, with $50 \% \mathrm{f} 1$. The influence of slug size, anisotropy and correlation length was also investigated. But for this new series, a constant number of 30 seeds, whatever the situation, was considered. The idea was to extend the validity of the preceding results. It appears, that for a given case, a larger 
number of seeds should be required to obtain a reprèsentative tertiary oil recovery distribution as the standard deviation is higher for the same number of 30 seeds. Moreover, in the anisotropic case and for the chosen high permeability ratio, due to numerical difficulties some simulations do not reach the final period investigated. In the isotropic case, the same influence of reduction of tertiary oil recovery with the correlation length can be found.

\section{Conclusions}

Simulations were performed for both two-layer and stochastically defined reservoirs.

The former simulations showed that within the range of slug size considered, the tertiary oil recovery increases with the slug size. There is however a high influence of the location of the less permeable facies when the permeability ratio is high too.

In our conditions, up to 20 or $50 \%$ of the reservoir correspond to three-phase systems. But there is no relationship between the extension of the three-phase region and the oil recovery. Gravity and water relative permeability are also determining.

There is a competition between gravitary effects and anisotropy. Anisotropy influences strongly the results and may be fruitful or not depending on the cases.

The latter simulations made it possible to draw the following conclusions:

- the number of equiprobable reservoir images in which simulations have to be performed to obtain representative oil recovery distribution are function of the correlation length and of the facies proportion.

- the increase of the heterogeneity correlation length reduces the oil recovery.

- the tertiary oil recovery may increase or not with the slug size depending on the heterogeneity location but also if permeability anisotropy occurs or not.

\section{Nomenclature}

I.S.U is used.

f1

f2

$\mathrm{k} 1$

$\mathrm{k} 2$

$\mathrm{mw}$

mo

mg

$\mathrm{Pb}$

$\mathrm{P}$

Sorw

Sorg more permeable facies

less permeable facies

f1 permeability

f2 permeability

water viscosity

oil viscosity

gas viscosity

bubble point

simulation pressure

Residual oil saturation to water

Residual oil saturation to gas

\section{References}

1. Caudle, B. H. and Dyes, A. B. "Improving miscible displacement by gas-water injection" Trans. AIME (1958) pp.213,281.

2. Stone, H. L. ,"Vertical conformance in an alternating water-miscible gas flood", SPE 11130, New Orleans, Sept 26-29, 1982.

3. Guzman, R. E., Giordano, D. ,Fayers, F. J. Aziz, K., Godi, A., "Three-phase flow in fieldscale simulations of gas and WAG injections", SPE 28897, London, Oct. 25-27,1994.

4. Stone,H. L. , "Estimation of three-phase relative permeability and residual oil data", $J$. Pet. Tech. vol. 12,4. pp.53-61, 1973.

5. Morel, D., Latil, M., "Basic study of sweep efficiency improvement by water alternate gas injection" , 4th European Symposium on Enhanced Oil Recovery,Hamburg Oct 27. $29,1987$.

6. Land. C. L. , "Calculation of imbibition relative permeability for two-and three-phase flow from rock properties", Trans. vol. 243, 1968.

7. Killough,J.E.,"Reservoir simulation with history-dependent saturation functions", SPEJ 02/1976 pp.37-48.

8. Minssieux, L.,Duquerroix. J-P. L., "WAG flow mechanisms in presence of residual oil",SPE 28623, New Orleans, Sept. 25-28, 1994.

9. Reference Manual TRITRI FRANLAB 1970. 